\title{
Validation of Global Digital Elevation Models in Lagos State, Nigeria
}

\author{
Arungwa I.D. ${ }^{1, *}$, Obarafo E.O. ${ }^{2}$ and Okolie C.J. ${ }^{3}$ \\ ${ }^{1}$ Department of Surveying and Geo-Informatics, Faculty of Engineering, Abia State University, Uturu, Nigeria \\ ${ }^{2}$ H.D. Surveys, Calabar, Cross River State, Nigeria \\ ${ }^{3}$ Department of Surveying and Geo-Informatics, Faculty of Engineering, University of Lagos, Lagos, Nigeria \\ Corresponding Author: *arungwaikenna@gmail.com
}

\begin{abstract}
Satellite-derived Digital Elevation Models (DEM) are fast replacing the classical method of elevation data acquisition by ground survey methods. The availability of free and easily accessible DEMs is no doubt of great significance and importance, and a valuable resource in the quest to accurately model the earth's surface topography. However, the suitability of Digital Elevation Models in simulating the topography of the earth at micro, local and regional scales is still an active area of research. The accuracy of Digital Elevation Models vary from one location to another. As such, it is important to conduct local and regional assessments to inform the global user community on the relative performance of these DEMs. This study evaluates the accuracy of the 30-metre Advanced Spaceborne Thermal Emission and Reflection Radiometer Global Digital Elevation Models version 2, the 1-kilometre GTOPO30, the 90-metre Shuttle Radar Topography Mission v4 and the 1-kilometre Shuttle Radar Topography Missionv2.1 Digital Elevation Models by validating with highly accurate GPS check-points over Lagos, Nigeria. With a Root Mean Square Error of $3.75 \mathrm{~m}$, the results show that Shuttle Radar Topography Mission v4 has the highest vertical accuracy followed by Shuttle Radar Topography Mission v2.1 (Root Mean Square Error: 5.73m), Advanced Spaceborne Thermal Emission and Reflection Radiometer (Root Mean Square Error: $21.70 \mathrm{~m}$ ), and GTOPO30 which shows the lowest vertical accuracy (Root Mean Square Error: $29.41 \mathrm{~m}$ ). By conducting the accuracy assessment of these products in Lagos, this study informs efforts directed at the exploitation of these Digital Elevation Models for topographic mapping and other scientific and environmental application.
\end{abstract}

Keywords: Digital Elevation Model, Topography, SRTM, ASTER GDEM, GTOPO30

\subsection{Introduction}

The availability of free and easily accessible Digital Elevation Models (DEMs) is no doubt of great significance and importance, and a valuable resource in the quest to accurately model earth's surface topography. According to Isioye and Obarafo (2010), the capacity to understand and model earth surface processes depends on the quality of the topographic data that is available in digital format. In the field of geodesy, Featherstone and Kirby (2000) noted that DEMs play an important role in determining a precise gravimetric geoid, computation of terrain corrections, direct topographical effects on gravity and indirect effects on geoid, and also to generate mean gravity anomalies.

Elkhrachy (2017) submits that global elevation datasets are inevitably subject to errors, mainly due to the methodology adopted in extracting elevation information and the various processing steps the models have undergone. He further noted that errors in DEMs comprise mainly of two components: the horizontal component, often referred as the positional accuracy of the $\mathrm{X}$ and Y components; and the vertical component or the accuracy of the attributes. He further pointed out that, the positional and attributive accuracy generally cannot be separated. The error may be due to an incorrect elevation value at the correct position, or a proper elevation for an incorrect position or any combination of these. It is important to note that no matter how rigorous the process of a DEM's construction is, it will invariably contain systematic or other measurement or estimation problems and may show 
uncertainties in the data due to poor representation (Olusina and Okolie, 2018). There are various approaches for ascertaining the extent of error in a DEM. A standard uncertainty measure is the Root Mean Square Error (RMSE) (Rinehart and Coleman, 1988). Another method is to determine if the DEM heights fall between contour elevations by using elevation histograms to show if there is a linear fit between contours (Reichenbach et al., 1993; Carrara et al., 1997). In addition, errors based on grid bias can be found by comparing drainage networks extracted by multiple rotations of the DEM (Charleux-Demargne and Puech, 2000).

Since the accuracy of satellite-derived DEMs vary from one location to another, it is important to conduct localised assessments. This study focuses on the 30-metre Advanced Spaceborne Thermal Emission and Reflection Radiometer Global DEM version 2 (ASTER GDEM2), the 1-kilometre GTOPO30, the 90-metre SRTM v4 and the 1-kilometre SRTM30 v2.1 DEMs. Several researchers have evaluated the accuracy of these DEMs (e.g. Hirano et al.,2003; Gorokhovich and Voustianiouk, 2006; Yastikli et al., 2006; Racoviteanu et al., 2007; Mangoua et al., 2008; Tighe and Chamberlain, 2009; Hirt et al.,2010; Hengl and Reuter, 2011; Arefi and Reinartz, 2011; Rexer and Hirt, 2014; Santillan and Makinano-Santillan, 2016; Elkhrachy, 2017). These accuracy assessments have provided valuable information to the global user community on their performances in different regions of the world. Although a number of studies have been conducted in Nigeria (e.g. Ozah and Kufoniyi, 2008; Isioye and Obarafo, 2010; Ojigi and Dang, 2010; Isioye et al., 2012; Nwilo et al., 2012; Nwilo et al., 2017), the available information in the literature on the relative performance of the ASTER, GTOPO30 and SRTM DEMs in the country is still inadequate. This study contributes to the existing knowledge by conducting an accuracy assessment of these DEM products at a test site in Lagos, Nigeria.

The 1 arc-second/30-metre Advanced Spaceborne Thermal Emission and Reflection Radiometer Global DEM version 2 - ASTER GDEM2, is a significant improvement over the earlier ASTER GDEM version 1 - GDEM1, which was released in 2009 (NASA JPL, 2011; Santillan and MakinanoSantillan, 2016). GDEM1 was found to have an overall accuracy of around 20 metres at the 95\% confidence level (ASTER GDEM Validation Team, 2011). It also had several artefacts associated with poor stereo coverage at high latitudes, cloud contamination and water masking issues. However, GDEM2 (released in 2011) has several improvements over GDEM1 such as the use of additional scenes to improve coverage, a smaller correlation kernel to yield higher spatial resolution, and an improved water mask (NASA/METI, 2011). The number of voids and artefacts in GDEM1 was substantially reduced in GDEM2. In Japan, GDEM2 was reported by the ASTER GDEM Validation Team to have a RMSE of $6.1 \mathrm{~m}$ in flat and open areas, and $15.1 \mathrm{~m}$ in mountainous areas largely covered by forest (Tachikawa et al., 2011). In the conterminous United States, Gesch et al. (2012) notes that the RMSE for GDEM2 was $8.68 \mathrm{~m}$ based on a comparison with more than 18,000 independent reference ground control points. The overall global accuracy of GDEM 2 at 95\% confidence level has been put at 17m (ASTER GDEM Validation Team, 2011). For this study, GDEM2 was obtained from the NASA/USGS Land Processes Distributed Active Archive Centre (LPDAAC) Global Data Explorer.

GTOPO30 is a global DEM with elevations regularly spaced at 30arc-seconds (approximately 1 kilometre) resolution. It covers the full extent of latitude from $90^{\circ} \mathrm{N}-90^{\circ} \mathrm{S}$, and the full extent of longitude from $180^{\circ} \mathrm{W}-180^{\circ} \mathrm{E}$. It is the result of a collaborative effort led by the staff at the United States Geological Survey (USGS) Earth Resources Observation and Science Data Centre. It was compiled from the following raster and vector sources of elevation information: Digital Terrain Elevation Data (50\% of global land area), Digital Chart of the World (29.9\% of global land area), USGS 1-degree DEMs (6.7\% of global land area), Army Map Service 1:1,000,000 scale maps (1.1\% of global land area), International Map of the World 1:1,000,000 scale maps (3.7\% of global land area), Peru 1:1,000,000 scale map ( $0.1 \%$ of global land area), New Zealand DEM ( $0.2 \%$ of global land area), and Antarctic Digital Database (8.3\% of global land area). The absolute vertical accuracy of GTOPO30 varies by location depending on the site-specific dataset used. Generally, the areas derived from the raster datasets have higher accuracy than those derived from the vector datasets. For example, the full resolution 3-arc second DTED and USGS DEMs have a vertical accuracy of $\pm 30 \mathrm{~m}$ linear error at the 90\% confidence level (Defense Mapping Agency, 1986; U.S. Geological Survey, 1993; GTOPO30 Readme, 2017). According to the GTOPO30 documentation, if this error distribution is assumed to be Gaussian with a mean of zero, the statistical standard deviation of the 
errors is equivalent to the RMSE. Under those assumptions, vertical accuracy expressed as $\pm 30 \mathrm{~m}$ linear error at $90 \%$ can also be described as a RMSE of 18metres. The estimated absolute vertical accuracy for the areas of GTOPO30 derived from each source, with the method of estimating the accuracy is given in the GTOPO30 Readme (2017).

The Shuttle Radar Topography Mission (SRTM) is the result of a collaborative effort by the National Aeronautics and Space Administration (NASA), the National Geospatial Intelligence Agency (NGA), the German Space Agency (DLR), and the Italian Space Agency (ASI) (Van Zyl, 2001; Rabus et al., 2003; Foni and Seal, 2004). The mission was launched on 11 February 2000 aboard the Space Shuttle Endeavour. Using radar interferometry, the SRTM DEM was produced for almost the entire globe. There are several resolution outputs available, including a 3 arc-second (version 4) and a 30 arcsecond (version 2.1) product for the world. The absolute vertical and horizontal accuracy of the data collected was reported to be $\pm 16 \mathrm{~m}$ (Rabus et al., 2003; Kellndorfer et al., 2004; Miliaresis and Paraschou, 2005; Kaab, 2005). SRTM DEMs have been shown to suffer from a number of gross, systematic and random errors propagated from the Synthetic Aperture Radar (SAR) imaging system (Koch and Lohmann, 2000; Ozah and Kufoniyi, 2008). Such errors are due to baseline tilt angle, baseline length, platform position, phase and slant range. Although SRTM data produced a number of voids due to lack of contrast in the radar image, a methodology based on spatial filtering was developed to correct this phenomenon (Dowding et al., 2004; Jarvis et al., 2004). SRTM v4 with voids filled in was obtained from the website of the Consultative Group for International Agriculture Research-Consortium for Spatial Information (CGIAR-CSI), while SRTM30 v2.1 was obtained from the USGS Earth Resources Observation and Science Data Centre archive.

\subsection{Materials and Methods}

\subsection{Study area}

The study area is Lagos State, a low-lying coastal state in south-west Nigeria located between longitudes $2^{\circ} 41^{\prime} 15^{\prime \prime}-4^{\circ} 22^{\prime} 00^{\prime \prime} \mathrm{E}$ and latitudes $6^{\circ} 20^{\prime} 10^{\prime \prime}-6^{\circ} 43^{\prime} 20^{\prime \prime} \mathrm{N}$. The state has a relatively stable terrain with minimal terrain undulations. Lagos is bounded in the north and east by Ogun State, in the west by the Republic of Benin and in the south by the Atlantic Ocean. About $40 \%$ of the State's total land area is covered by water and wetlands. The State has many notable features including lagoons and creeks, wetlands, barrier islands, beaches and estuaries, the Iddo Port, Apapa Port etc. (Osei et al., 2006; Odumosu et al., 2015). Figure 1 shows a map of Lagos State. Based on the old Local Government set-up, Lagos State has 20 Local Government Areas (LGAs). The state has a very diverse and fast-growing population, resulting from accelerated migration from all over the country as well as from neighbouring countries.

\subsection{Data acquisition}

ASTER GDEM2, GTOPO30, SRTM v4 and SRTM30 v2.1 DEMs were obtained from their respective online portals. The DEMs are provided in tiles and are referenced to the WGS84 datum. Table 1 shows the characteristics of the DEMs. Also, the three-dimensional coordinates of 581 first and second order GPS controls (check-points) with grid coordinates in Universal Transverse Mercator (UTM) system referenced to WGS84 datum were acquired from the Office of the Surveyor General of Lagos State. The GPS controls serve as check-points to validate the accuracy of the DEMs. The spatial distribution of the GPS control points in Lagos state used for the study is shown in Figure 2. Since the GPS data is of high accuracy, independent and sufficiently precise, it will give reasonable estimates in the accuracy assessment (Obarafo, 2015; Olusina and Okolie, 2018).

\subsection{Data processing}

The data processing consists of two steps:

1. Datum harmonization and height conversion

2. Comparison of DEM data with reference GPS points. 


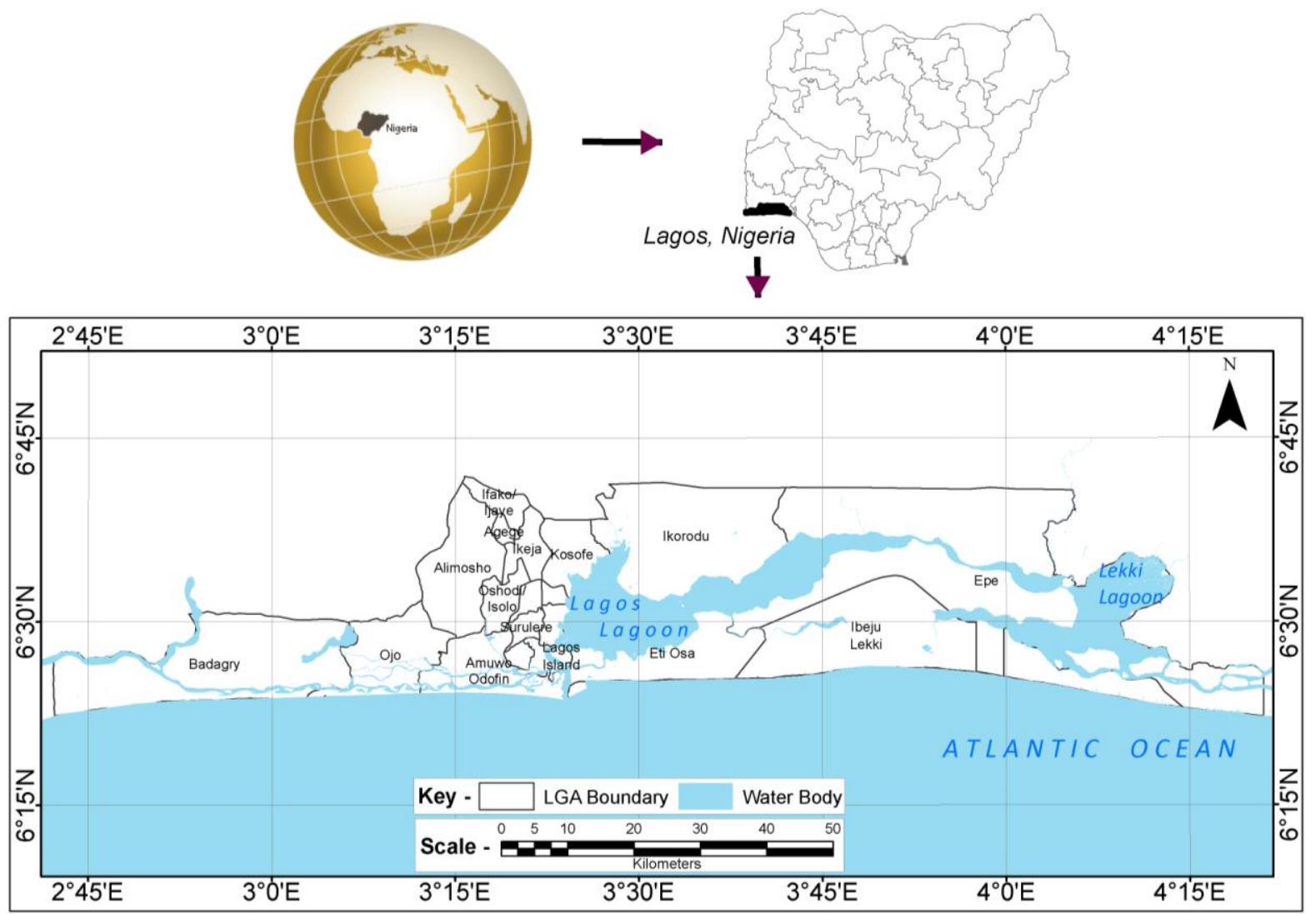

Figure 1: A map of Lagos State

Table 1: DEM datasets and characteristics

\begin{tabular}{|c|c|c|c|c|c|c|}
\hline Dataset & Source & $\begin{array}{c}\text { Coordinate } \\
\text { System }\end{array}$ & $\begin{array}{c}\text { Geoid } \\
\text { Reference }\end{array}$ & $\begin{array}{c}\text { Vertical } \\
\text { Units }\end{array}$ & Height system & Resolution \\
\hline $\begin{array}{l}\text { ASTER GDEM } \\
\text { v2 }\end{array}$ & $\begin{array}{l}\text { NASA/ } \\
\text { METI }\end{array}$ & \multirow{4}{*}{$\begin{array}{c}\text { Geodetic } \\
(\varphi, \lambda, H) \\
\text { WGS84 }\end{array}$} & \multirow{4}{*}{$\begin{array}{l}\text { WGS84/ } \\
\text { EGM96 }\end{array}$} & \multirow{4}{*}{ Metres } & \multirow{4}{*}{ Orthometric } & 1 arc-second $(30 \mathrm{~m})$ \\
\hline GTOPO30 & USGS & & & & & 30 arc-seconds $(1 \mathrm{~km})$ \\
\hline SRTM v4 & \multirow{2}{*}{$\begin{array}{l}\text { NASA/ } \\
\text { NGA }\end{array}$} & & & & & 3 arc-seconds $(90 \mathrm{~m})$ \\
\hline SRTM30 v2.1 & & & & & & 30 arc-seconds $(1 \mathrm{~km})$ \\
\hline
\end{tabular}

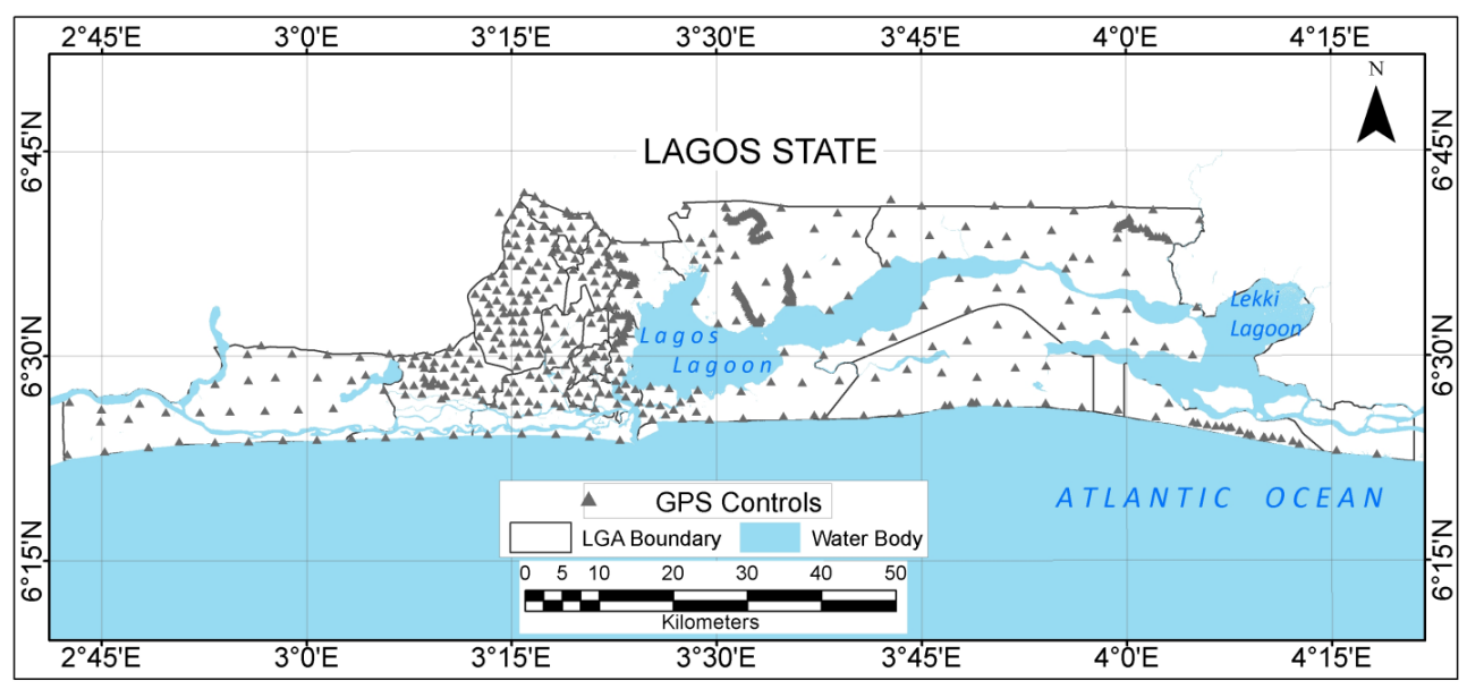

Figure 2: A map showing the location of GPS controls in the study area

\subsubsection{Data harmonization and height conversion}

The DEMs are provided in a geographic coordinate system and so it was necessary to reproject the data in ArcGIS 10.3 to a UTM system. This transformation helped to overcome linear measurement 
difficulties and preserve geometric properties of the DEMs. The orthometric equivalent of the GPS ellipsoidal heights was derived using Equation 1 (Elkhrachy, 2017):

$H=h-N$
where:
$H \quad$ Orthometric height
$h \quad$ Ellipsoidal height
$N \quad$ Geoid height/undulation

The relationship between the orthometric height, ellipsoidal height and the geoid height is shown in Figure 3. $N$ was computed using the GeoidEval online geoid height calculator. GeoidEval computes the geoid height of any given point based on global geoid models (EGM96 or EGM2008). To ensure consistency with the vertical datum of the DEMs, the geoidal heights were computed based on the EGM96 geoid model.

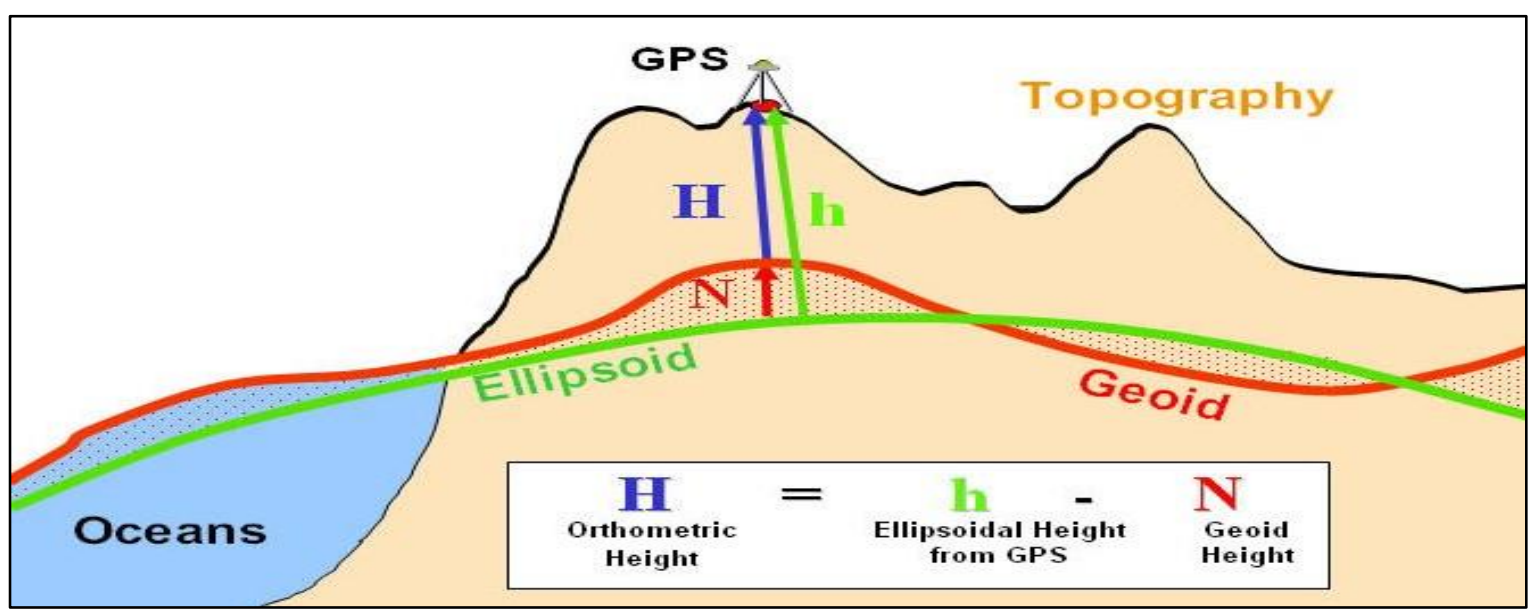

Figure 3: Relationship between orthometric, ellipsoidal and geoid heights (Source: ELTE, 2017)

\subsubsection{Comparison of DEM data with reference GPS points}

In ArcGIS, the GPS points were overlaid on the DEMs. Next, using the 'extract values to points' tool on ArcGIS Spatial Analyst, elevations were extracted from the DEMs at points coincident with the GPS data. The DEM point elevations were then subtracted from the GPS point elevations and the differences were tabulated. To evaluate the accuracy of the elevations from the DEMs with respect to the reference GPS control points, the following goodness of fit statistics were computed -elevation differences, Pearson's coefficient of correlation (R), the coefficient of determination $\left(\mathrm{R}^{2}\right)$, and Root Mean Square Error (RMSE). Positive elevation differences represent locations where the DEM is below the GPS elevation, while negative differences occur at locations where the DEM is above the GPS elevation. The mean difference indicates if a DEM has an overall vertical positive or negative offset from the true ground level (Gesch et al., 2012; Santillan and Makinano-Santillan, 2016).

\subsection{Results and Discussion}

After a sequential elimination of outlier points based on physical inspection in the initial comparison, the summary of coincident elevations from the DEMs and reference GPS points are shown in Table 2. The point elevations from the ASTER GDEM2, GTOPO30, SRTM v4 and SRTM30 v2.1 DEMs are denoted by HASTER, HGTOPO30, HSRTMv4 and HSRTM30v2.1 respectively. Across the terrain, the GPS elevations range from $0.17-66.89 \mathrm{~m}$. The elevation ranges at all sites from the DEMs are ASTER (min: 0m; max: 97m), GTOPO30 (min: 35m; max: 64m), SRTM v4 (min: 0m; max: 67m), and SRTM30 v2.1 (min: 0m; max: 68m). The mean elevations are as follows: ASTER (mean: 28.95m), GTOPO30 (mean: 42.77m), SRTM v4 (mean: $18.17 \mathrm{~m}$ ), and SRTM30 v2.1 (mean: $17.08 \mathrm{~m}$ ). Figure 4(a-d) presents the scatter plots of the DEMs data against the reference GPS points fitted with 95\% confidence bounds (shown by the red dotted lines). The highest agreement with the GPS 
reference data is seen in SRTM v4 $\left(\mathrm{R}^{2}=0.95\right)$ followed by SRTM30 v2.1 $\left(\mathrm{R}^{2}=0.86\right)$, ASTER $\left(\mathrm{R}^{2}=\right.$ $0.40)$, and GTOPO30 $\left(\mathrm{R}^{2}=0.35\right)$ which shows the lowest agreement.

Table 2: Comparison of elevations from the DEMs and reference GPS points

\begin{tabular}{|c|c|c|c|c|c|c|c|c|c|}
\hline & $\begin{array}{c}\mathrm{H}_{\text {ASTER }} \\
(\mathrm{m})\end{array}$ & \multicolumn{2}{|c|}{$\mathrm{H}_{\mathrm{GPS}}(\mathrm{m})$} & $\begin{array}{c}\mathrm{H}_{\mathrm{GTOPO} 30} \\
(\mathrm{~m})\end{array}$ & $\mathrm{H}_{\mathrm{GPS}}(\mathrm{m})$ & $\begin{array}{c}\mathrm{H}_{\text {SRTMv4 }} \\
(\mathrm{m})\end{array}$ & $\mathrm{H}_{\mathrm{GPS}}(\mathrm{m})$ & $\mathrm{H}_{\mathrm{SRTM} 30 v 2.1}(\mathrm{~m})$ & $\mathrm{H}_{\mathrm{GPS}}(\mathrm{m})$ \\
\hline Count & \multicolumn{2}{|c|}{570} & \multicolumn{2}{|c|}{580} & \multicolumn{2}{c|}{569} & \multicolumn{2}{c|}{580} \\
\hline Min & 0.00 & 0.17 & 35.00 & 0.17 & 0.00 & 0.17 & 0.00 & 0.17 \\
\hline Max & 97.00 & 66.89 & 64.00 & 66.89 & 67.00 & 66.89 & 68.00 & 66.89 \\
\hline Mean & 28.95 & 16.27 & 42.77 & 16.26 & 18.17 & 16.41 & 17.08 & 16.26 \\
\hline
\end{tabular}
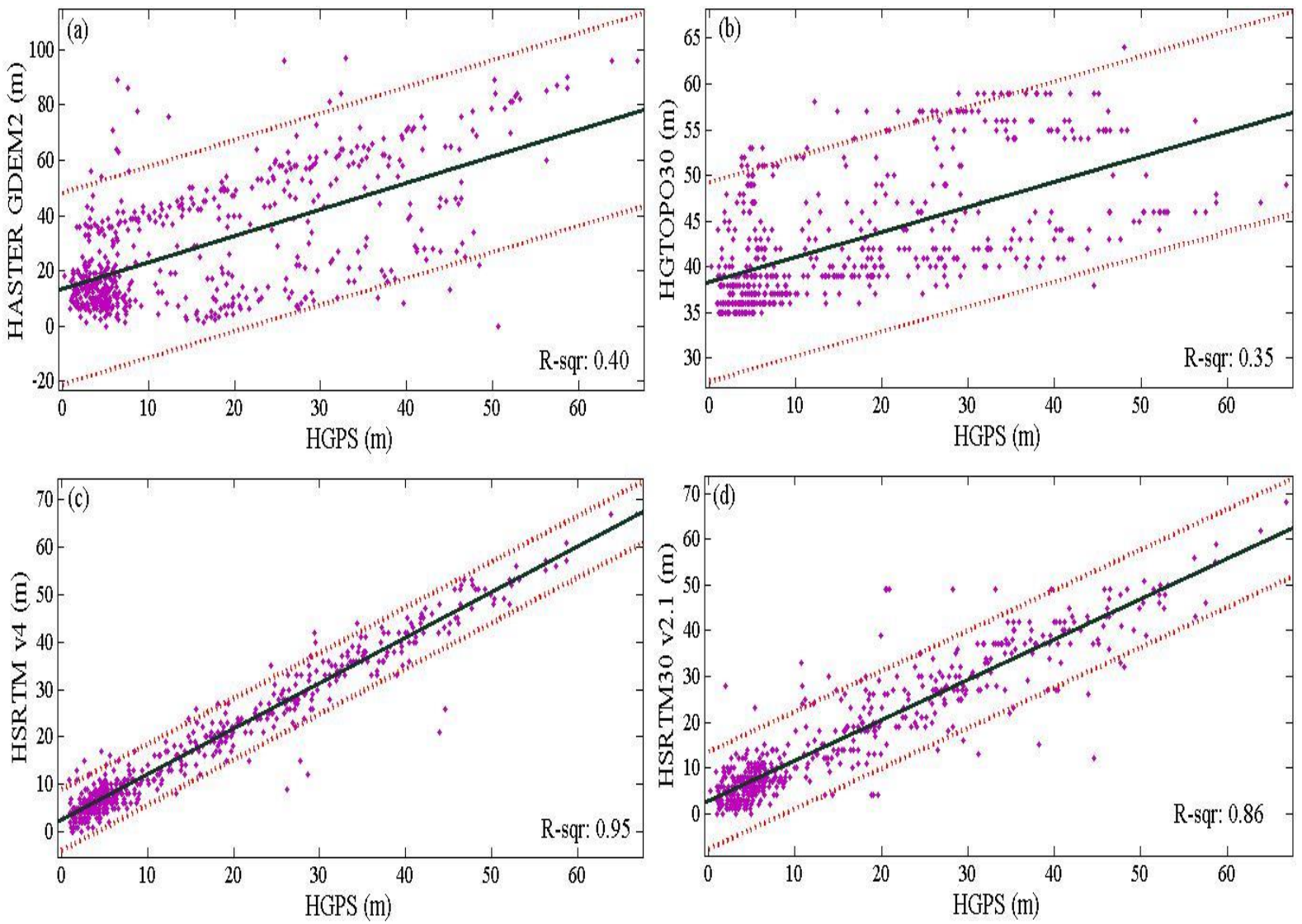

Figure 4: The graphic expression of $95 \%$ confidence zone for DEM comparison with reference GPS points (a) ASTER (b) GTOPO30 (c) SRTM v4, and (d) SRTM30 v2.1

Figure 5(a-d) presents a graphical comparison of the magnitude of elevation differences. In the analysis of correlation with the GPS points, Table 3 presents the Pearson's R for each DEM. It can be seen that there is a significant relationship between the ASTER DEM's elevations and its residuals. However, there is no clear relationship between the residuals and elevations for all other DEMs. For other DEMs therefore, it cannot be said that the errors in the DEM increase with elevation or otherwise. As a matter of fact, they show relatively weak correlation with elevation (Table 3 ). For the ASTER GDEM however, the errors show some significant negative correlation with the DEM elevation $(R=-0.755)$. This shows an increase in error with respect to increasing DEM elevations within the study area. 

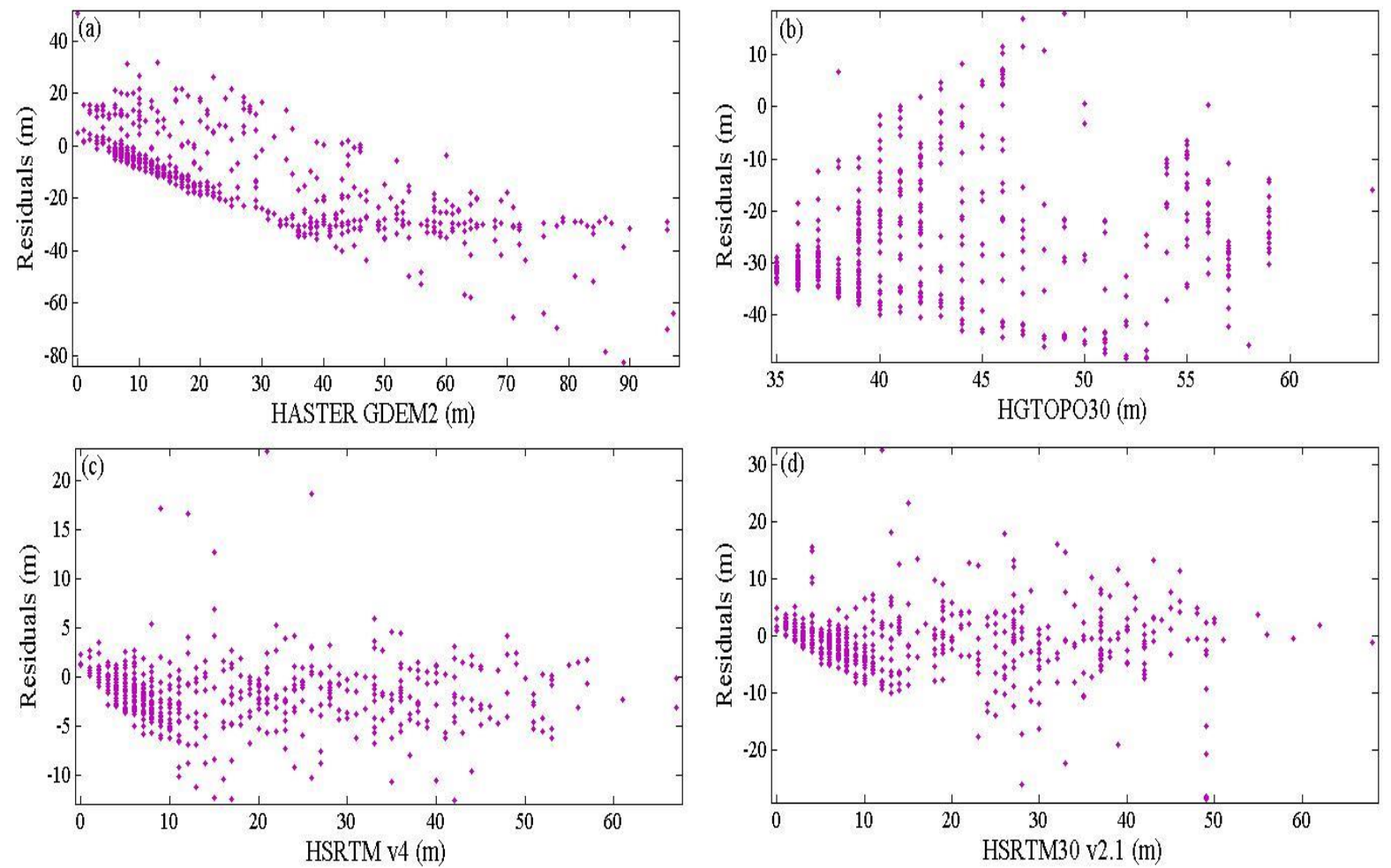

Figure 5: Graphical comparison of the magnitude of elevation differences (a) ASTER (b) GTOPO30 (c) SRTM v4 and (d) SRTM30 v2.1

Table 3: Pearson Correlation Analysis

\begin{tabular}{|c|c|c|c|c|}
\hline & ASTER & GTOPO30 & SRTM v4 & SRTM30 v2.1 \\
\cline { 1 - 4 } Pearson's R & -0.755 & 0.098 & -0.062 & -0.089 \\
\hline
\end{tabular}

Table 4 shows a summary of the differences between the DEMs and the GPS elevations. The DEM point elevations were subtracted from the elevations of the GPS points to yield the vertical differences

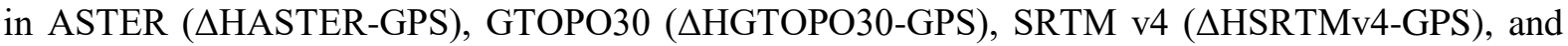
SRTM30 v2.1 ( $\triangle$ HSRTM30v2.1-GPS) respectively. A larger percentage of the residuals in Figure 5(a-d) fall below zero implying that all four DEM products overestimated the terrain elevation in the area under study. This tendency to overestimate the true ground elevation is further reflected in the mean differences between the DEMs and GPS points (ASTER: $-12.68 \mathrm{~m}$, GTOPO30: $-26.51 \mathrm{~m}$; SRTM v4: $-1.76 \mathrm{~m}$; SRTM30 v2.1: $-0.82 \mathrm{~m}$ ). With a RMSE of $3.75 \mathrm{~m}$, SRTM v4 has the highest vertical accuracy followed by SRTM30 v2.1 (RMSE: 5.73m), ASTER GDEM2 (RMSE: 21.70m), and GTOPO30 which shows the lowest vertical accuracy (RMSE: 29.41m).

The abysmal performance of ASTER GDEM, (with mean error and RMSE values of $-12.68 \mathrm{~m}$ and $21.70 \mathrm{~m}$ respectively) though buttresses the fact that accuracy of DEM vary in space, it however challenges the opinion that accuracy of DEM is a function of resolution - this evidently wasn't the case between ASTER of 1" resolution and SRTMs of 3" and 30" resolution. The probable reason for this poor performance may not be unconnected to the presence of voids and artefacts in the DEM as reported by Santillan et al. (2016) and relatively limited number of GCP's that were used in its creation as hinted by Racoviteanu et al. (2007). The research also adds to the body of literature reporting a poor performance of ASTER GDEM (e.g. Santillan et al., 2016; Ioannidis et al., 2014, Racoviteanu et al., 2007).

Another important finding of the research as seen in Figure 5(a) is that errors in ASTER GDEM increases with altitude over the study area. This of course is to the observation of Racoviteanu et al., (2007), in Nevado Coropuna, Peru. 
Table 4: Summary of the elevation differences (residuals) between the DEMs and GPS points

\begin{tabular}{|c|c|c|c|c|}
\hline & $\begin{array}{c}\Delta \mathrm{H}_{\text {ASTER-GPS }} \\
(\mathrm{m})\end{array}$ & $\begin{array}{c}\Delta \mathrm{H}_{\text {GTOPO30-GPS }} \\
(\mathrm{m})\end{array}$ & $\begin{array}{c}\Delta \mathrm{H}_{\text {SRTMv4-GPS }} \\
(\mathrm{m})\end{array}$ & $\begin{array}{c}\Delta \mathrm{H}_{\text {SRTM30v2.1-GPS }} \\
(\mathrm{m})\end{array}$ \\
\hline Count & 570 & 580 & 569 & 580 \\
\hline Min & -82.59 & -48.32 & -12.59 & -28.53 \\
\hline Max & 50.60 & 17.89 & 22.98 & 32.61 \\
\hline MMSE & -12.68 & -26.51 & -1.76 & -0.82 \\
\hline
\end{tabular}

\subsection{Conclusion and Recommendations}

The results show that the four satellite DEMs (ASTER GDEM2, GTOPO30, SRTMv4 and SRTM30 v2.1) tend to overestimate the true ground elevation. The vertical accuracy for SRTM v4 and SRTM30 v2.1 in this study $(3.75 \mathrm{~m}$ and $5.73 \mathrm{~m}$ respectively) surpasses the $16 \mathrm{~m}$ accuracy requirement presented in the original SRTM specification. SRTM v4 is the best fitting DEM in this study. It is also clear from results that SRTM30 v2.1 is fairly comparable to SRTM v4. NASA/METI (2011) gave the overall accuracy of ASTER GDEM2 to be around $17 \mathrm{~m}$ at the $95 \%$ confidence level. However, with a vertical accuracy of $21.70 \mathrm{~m}$ in this study, GDEM2 does not meet up with this requirement. Although of a higher spatial resolution, the accuracy of GDEM2 does not even surpass or compare favourably with that of SRTM v4 and SRTM30 v2.1. Evidently, the accuracy of a DEM does not necessarily increase with improvements in its spatial resolution. The probable reason for this poor performance may not be unconnected to the presence of artefacts in the DEM. This study has also shown that the errors in the ASTER DEM are amplified with increasing altitude. GTOPO30 was assembled from a wide range of raster and vector datasets. As such, it might be difficult to narrow down the cause of its poor performance. However, it can still be used as a substitute in areas not covered by SRTM, especially in mountainous areas. The overestimation tendency exhibited by all four DEMs within the study area is surely an important finding for users of these products and this must be considered when making decisions concerning their fitness for the purpose of any application.

Higher resolution DEMs such as the 5-metre ALOS World 3D and the 12-metre World DEM with reported higher vertical accuracies have since been available. However, the cost of acquisition still limits their usage by the global user community. As such, freely available DEMs such as ASTER, GTOPO30 and SRTM will continue to be a valuable resource for many scientific and engineering applications such as floodplain mapping, disaster vulnerability assessment, hydrological and geological studies, infrastructure planning, environmental management and gravimetric geoid modelling studies. The results of this study have contributed to the body of literature on performance assessment of satellite-derived digital elevation models. This study recommends the use of SRTM v4 and SRTM30 v2.1 in mapping the earth's topography particularly within the study area or in other regions with similar terrain characteristics. From the site-specific results here, ASTER GDEM2 and GTOPO30 might still be regarded as research-grade products. Going further, future research can study the relative performance of these DEMs in varying landscapes to determine the impact of aboveground obstructions and land cover, which block satellite pulses from having direct contact with the bare earth.

\section{Acknowledgement}

The authors are grateful to the Office of the Surveyor General of Lagos State for the provision of coordinates of GPS controls in the State for use in the accuracy assessment.

\section{References}

Arefi, H. and Reinartz, P. (2011). Accuracy Enhancement of ASTER Global Digital Elevation Models Using ICESat Data. Remote Sensing, 3(7), pp. 1323-1343. doi: 10.3390/rs3071323 
ASTER GDEM Validation Team (2011). ASTER Global Digital Elevation Model Version 2 Summary of Validation Results. August 31, 2011.

Carrara, A., Bitelli, G., and Carla, R. (1997). Comparison of Techniques for Generating Digital Terrain Models from Contour Lines. International Journal of Geographical Information Science, 11(5), pp. 451-473.

Charleux-Demargne, J. and Puech, C. (2000). Quality Assessment for Drainage Networks and Watershed Boundaries extraction from a Digital Elevation Model (DEM). In $8^{\text {th }}$ ACM Symposium on GIS, pp. 89-94, Washington, D.C.

Defence Mapping Agency (1986). Defence Mapping Agency product specifications for Digital Terrain Elevation Data (DTED) (2nd ed.). Defence Mapping Agency Aerospace Center, St. Louis, Missouri, pp. 1-26.

Dowding, S., Kuuskivi, T. and Li, X. (2004). Void fill of SRTM Elevation Data —Principles, Processes and Performance. Proceedings of the Conference "ASPRS Images to Decision: Remote Sensing Foundation for GIS Applications", Kansas City, MO, September 12-16.

Elkhrachy, I. (2017). Vertical Accuracy Assessment for SRTM and ASTER Digital Elevation Models: A case study of Najran city, Saudi Arabia. Ain Shams Engineering Journal, http://dx.doi.org/10.1016/j.asej.2017.01.007

ELTE Online (2017). Vertical Geo-reference.

http://elte.prompt.hu/sites/default/files/tananyagok/MapGridsAndDatums/ch07.html (Date accessed: 21 October, 2017).

Featherstone, W.E. and Kirby, J.F. (2000). The Reduction of Aliasing in Gravity Anomalies and Geoid Heights using Digital Terrain Data. Geophys. J. Int., 141, pp. 204- 214.

Foni, A. and Seal, D. (2004). Shuttle Radar Topography Mission: An Innovative Approach to Shuttle Orbital Control. Acta Astronautica, 54, pp. 565-570.

Gesch, D.B., Michael, J., Oimoen, Z.Z., David, J.M. and Jeffrey, J.D. (2012).Validation of the ASTER Global Digital Elevation Model Version 2 over the conterminous United States. In: Proceedings of the $22^{\text {nd }}$ Congress of the International Society for Photogrammetry and Remote Sensing: Imaging a sustainable future, Melbourne, Australia.

Gorokhovich, Y. and Voustianiouk, A. (2006). Accuracy Assessment of the processed SRTM-based Elevation data by CGIAR using field data from USA and Thailand and its relation to the Terrain Characteristics. Remote Sensing of Environment, 104, pp. 409-415.

GTOPO30 Readme (2017). GTOPO30 Documentation https://ta.cr.usgs.gov/GTOPO30 (Date accessed: 17 October, 2017)

Hengl, T. and Reuter, H. (2011). How accurate and usable is GDEM? A statistical assessment of GDEM using LiDAR data. Geomorphometry.org/2011.

Hirano, A., Welch, R. and Lang, H. (2003). Mapping from ASTER Stereo Image Data: DEM Validation and Accuracy Assessment. International Journal of Photogrammetry and Remote Sensing, 57(5-6), pp. 356-370.

Hirt, C., Filmer, M.S. and Featherstone, W.E. (2010). Comparison and Validation of the recent freely available ASTER-GDEM ver1, SRTM ver4.1 and GEODATA DEM-9S ver3 Digital Elevation Models over Australia. Australian Journal of Earth Sciences, 57(3), pp. 337-347. 
Isioye O. A., Jobin, P. and Youngu, T.T. (2012). Assessment of Digital Elevation Models (DEM) from different sources. Nigerian Journal of Surveying and Geoinformatics, 4(1), pp. 25 - 38.

Isioye, O.A. and Obarafo, E.O. (2010). Shuttle Radar Topography Mission (SRTM) Elevation data: A contemporary Global Elevation Model for describing the topography of Zaria and its environs. Ife Research Publications in Geography (IRPG), 9(1), pp. 221-245.

Jarvis, A., Rubiano, J., Nelson, A., Farrow, A. and Mulligan, M. (2004). Practical use of SRTM data in the tropics - comparisons with digital elevation models generated from cartographic data. Working Document, Vol. 198. Centro Internacional de Agricultura Tropical (CIAT) 32 pp.

Kaab, A. (2005). Combination of SRTM3 and repeat ASTER data for deriving alpine glacier flow velocities in the Bhutan Himalaya. Remote Sensing of Environment, 94, pp. 463-474.

Kellndorfer, J., Walker, W., Pierce, L., Dobson, C., Fites, J.A., et al. (2004).Vegetation height estimation from Shuttle Radar Topography Mission and National Elevation Datasets. Remote Sensing of Environment, 93, pp. 339-358. doi:10.1016/j.rse.2004.07.017.

Koch, A. and Lohmann, P. (2000). Quality Assessment and Validation of Digital Surface Models derived from the Shuttle Radar Topography Mission (SRTM), IAPRS, Vol. XXXIII, Amsterdam.

Mangoua, F.H. and Goïta, K. (2008). A Comparison between Canadian Digital Elevation Data (CDED) And SRTM Data of Mount Carleton in New Brunswick (Canada) The International Archives of the Photogrammetry, Remote Sensing and Spatial Information Sciences. Vol. XXXVII. Part B4. Beijing 2008.

Miliaresis, G.C. and Paraschou, C.V.E. (2005).Vertical Accuracy of SRTM DTED Level 1 of Crete. International Journal of Applied Earth Observation and Geoinformation, 7, pp. 49-59.

NASA JPL (2011). ASTER Global Digital Elevation Map Announcement, NASA Jet propulsion Laboratory.

NASA/METI (2011).ASTER GDEM 2 Readme. October 2011.

Nwilo, P.C., Ayodele, E.G. and Okolie, C.J. (2017). Determination of the Impacts of Landscape Offsets on the 30-metre SRTM DEM through a comparative analysis with Bare-Earth Elevations. FIG Peer Review Journal, 21 pps. ISSN No 2412-916X. Available at: http://fig.net/resources/publications/prj/showpeerreviewpaper.asp?pubid=8560. [Accessed June, 2017].

Nwilo, P.C., Olayinka, D.N., Okolie, C.J. and Adzandeh, E.A. (2012).Transformation of Shuttle Radar Topography Mission (SRTM) Digital Elevation Data to Nigerian Height System. FUTY Journal of the Environment, 7(1), pp. 73-89. http://dx.doi.org/10.4314/fje.v7i1.6.

Obarafo, E.O. (2015). Accuracy Enhancement of ASTER GDEM using Weight Estimation Regression Model. M.Sc. thesis (unpublished). University of Nigeria, Enugu.

Odumosu, J.O., Ajayi, O.G., Idowu, F.F. and Adesina, E.A. (2015).Evaluation of the various orthometric height systems and the Nigerian scenario - A case study of Lagos State. Journal of King Saud University - Engineering Sciences, http://dx.doi.org/10.1016/j.jksues.2015.09.002

Ojigi, M.L. and Dang, B.A. (2010). 3-Dimensional Data Validation of Shuttle Radar Topographic Mission (SRTM) in Lokoja Area of Nigeria. Nigerian Journal of Surveying and Geoinformatics, 3(1), pp. 67-85.

Olusina, J.O. and Okolie, C.J. (2018). Visualization of Uncertainty in 30m Resolution Global Digital Elevation Models: SRTM v3.0 and ASTER v2. Nigerian Journal of Technological Development, 15(3), pp. 77-83. http://www.njtd.com.ng/index.php/njtd/article/view/126/108 
Osei, A.J., Merem, E.C. and Twumasi, Y.A. (2006). Use of GIS and Remote Sensing Technology as a Decision Support Tool in Land Administration - The Case of Lagos, Nigeria. In: Proceedings of Promoting Land Administration and Good Governance 5th FIG Regional Conference Accra, Ghana, March 8-11, 2006.

Ozah, A.P. and Kufoniyi, O. (2008). Accuracy assessment of Contour Interpolation from 1:50,000 Topographical maps and SRTM data for 1:25,000 Topographical Mapping. The International Archives of the Photogrammetry, Remote Sensing and Spatial Information Sciences. XXXVII. Part B7. Beijing 2008.

Rabus, B., Eineder, M., Roth, A. and Bamler, R. (2003). The Shuttle Radar Topography Mission - a new class of Digital Elevation Models acquired by spaceborne Radar. ISPRS Journal of Photogrammetry and Remote Sensing, 57, pp. 241-262.

Racoviteanu, A.E., Manley, W.F., Arnaud, Y. and Williams, M.W. (2007). Evaluating Digital Elevation Models for Glaciologic Applications: An example from Nevado Coropuna, Peruvian Andes. Global and Planetary Change ,59, pp. 110-125.

Reichenbach, P., Pike, R.J., Acevedo, W. and Mark, R.K. (1993).A new Landform map of Italy in Computer-shaded. Relief Bollettino Geodesia a Scienze Affini, 52, pp. 22-44.

Rexer, M. and Hirt, C. (2014). Comparison of Free High-Resolution Digital Elevation Datasets (ASTER GDEM2, SRTM v2.1/v4.1) and Validation against Accurate Heights from the Australian National Gravity Database. Australian Journal of Earth Sciences, pp. 1-15, doi: 10.1080/08120099.2014.884983.

Rinehart, R.E. and Coleman, E.J. (1988). Digital Elevation Models produced from Digital Line Graphs. In: Proceedings of the ACSM-ASPRS Annual Convention, Volume 2, 291-299, American Congress on Surveying and Mapping, American Society for Photogrammetry and Remote Sensing.

Santillan, J.R. and Makinano-Santillan, M. (2016).Vertical Accuracy Assessment of 30-m Resolution ALOS, ASTER, and SRTM Global DEMs over North-Eastern Mindanao, Philippines. International Archives of the Photogrammetry, Remote Sensing and Spatial Information Sciences, XLI (B4), 149156. doi: 10.5194/isprs-archives-XLI-B4-149-2016.

Tachikawa, T., Hato, M., Kaku, M. and Iwasaki, A. (2011). Characteristics of ASTER GDEM version 2. International Geoscience and Remote Sensing Symposium (IGARSS), art.no.6050017, pp. 36573660 .

Tighe, M.L. and Chamberlain, D. (2009). Accuracy Comparison of the SRTM, ASTER, NED, NEXTMAP USA Digital Terrain Model over several USA Study Sites. ASPRS/MAPPS 2009 Fall Conference. November 16-19, 2009 San Antonio, Texas.

U.S. Geological Survey, 1993. Digital elevation models, data user guide 5. Reston, Virginia, 50 pp. Available at: ftp://mapping.usgs.gov/pub/ti/DEM/demguide/

Van Zyl, J.J. (2001). The Shuttle Radar Topography Mission (SRTM): a breakthrough in remote sensing of topography. Acta Astonautica, 48(5-12), pp. 559-565.

Yastikli, N., Kocak, G. and Buyuksalih, G. (2006). Accuracy and Morphological Analyses of GTOPO30 and SRTM X -C Band DEMs in the test area Istanbul. Paper presented at ISPRS Workshop on Topographic Mapping from Space (with Special Emphasis on Small Satellites), Ankara, Turkey, February 14-16. 